\title{
A CONTABILIDADE GOVERNAMENTAL E O CALENDÁRIO ELEITORAL: UMA ANÁLISE EMPÍRICA SOBRE UM PAINEL DE MUNICÍPIOS DO RIO DE JANEIRO NO PERÍODO 1998 - 2006
}

\section{GOVERNMENT ACCOUNTING AND ELECTORAL AGENDA IN RIO DE JANEIRO, BRAZIL: AN EMPIRICAL ANALYSIS OF A PANEL OF MUNICIPALITIES DURING 1998 - 2006}

\author{
KLEBER VASCONCELLOS DE OLIVEIRA \\ Mestre em Ciências Contábeis pela \\ Universidade do Estado do Rio de Janeiro \\ Analista na Financiadora de Estudos e Projetos \\ Rio de Janeiro/RJ, Brasil \\ E-mail: kleber.vasconcellos@gmail.com
}

\author{
FREDERICO ANTONIO AZEVEDO DE CARVALHO \\ Doutor em Economia pela \\ Universidade Católica de Louvain, Bélgica \\ Professor Adjunto no Programa de Mestrado em Ciências \\ Contábeis da Universidade do Estado do Rio de Janeiro \\ Rio de Janeiro/RJ, Brasil \\ E-mail: fdecarv@gmail.com
}

\section{Resumo}

Com apoio na teoria dos ciclos políticos, este trabalho pretende analisar o comportamento das contas municipais fluminenses, entre 1998 e 2006, a fim de detectar eventuais "comportamentos cíclicos" associados ao calendário eleitoral. Usando dados em painel para estimar diversas equações de regressão múltipla, examinam-se rubricas específicas do Orçamento e dos Balanços municipais a fim de testar hipóteses sobre a existência de manipulações de caráter eleitoral executadas pelos governantes. Os resultados sugerem que 0 calendário eleitoral exerce influência (estatisticamente) significativa sobre o comportamento dos prefeitos, mesmo descontando certos efeitos específicos a cada município (a população, por exemplo). Estas manipulações cíclicas também aconteceram em alguns itens da despesa nos anos de 2002 e 2006, indicando uma movimentação política das prefeituras no sentido de contribuírem com seus partidos nas eleições para Governador, Presidente e Congresso Nacional. A coincidência partidária entre prefeitura e estado e/ou União apresentou relação inversa, ou seja, pertencer ao mesmo partido do governador e/ou do presidente significa uma redução em determinados gastos municipais, sugerindo uma espécie de "pacto de ajuste fiscal" entre estes níveis de governo.

Palavras-chave: Contabilidade Governamental; ciclos políticos; dados em painel.

\begin{abstract}
Based on the theory of political-economic cycles this paper investigates accounting data relatied to municipal governments in Rio de Janeiro, Brazil, aiming to detect whether mayors displayed cyclical behavior during the period 1998-2006, including electoral years 2002 and 2006. Using panel data corresponding to a convenience sample including forty municipalities, allowed the selected variables from municipal budgets and balance sheets to be analyzed using a linear regression framework. Findings suggest that electoral agendas cyclically impact in a significant way upon mayor behavior. For some expenditure items cyclical manipulations coincided with electoral years and seem to indicate that mayors are indeed prone to helping their parties both in executive and parliamentary elections, either in state or national levels. However the partisan coincidence between mayors and either governors or the president has shown a negative relationship so that their revealed behavior points in fact to a substitution among government levels.
\end{abstract}

Key words: Government Accounting, political cycles, regression with panel data. 


\section{INTRODUÇÃO}

É crescente a exigência da sociedade para que os governantes demonstrem os resultados de suas "formas de governar", maximizando assim os níveis de transparência, um dos pilares da Lei de Responsabilidade Fiscal. Em sintonia com as demandas sociais por maior transparência, a Contabilidade, como ciência e como prática profissional, vem assumindo seu papel de intermediador da comunicação entre o governo e os interessados nas informações públicas. A divulgação de informações mais claras, mais confiáveis e mais transparentes caracteriza uma legítima preocupação dos tomadores de decisão, pois os diversos agentes que interagem com o Governo estão cada vez mais interessados na correta aplicação de seus tributos. A chamada accountability das ações governamentais ultrapassa os mandatos dos eleitos, porque sem informações confiáveis, relevantes e oportunas não é possível ativar os mecanismos de responsabilização ao longo do tempo.

0 fato de que os resultados de eleições são diretamente influenciados pelo desempenho da política econômica e/ou fiscal em um país pertence, hoje, ao consenso social. Ás vésperas de uma eleição, um governante dificilmente anunciaria medidas econômicas, tais como um aumento de impostos, que pudessem "desagradar" os eleitores. A partir de 1998, a possibilidade de reeleição, inserida pela Constituição, abriu espaço para a ocorrência de certas manipulações nas finanças públicas com vistas a impactar positivamente o eleitorado. Além disso, o grande volume de recursos envolvidos no orçamento público pode transformá-lo em poderosa arma de manobra eleitoral, na medida em que o chefe do executivo pode manipular a execução orçamentária com fins eleitoreiros.

De um lado estão os benefícios de permanência do poder, tendo em vista que serão usufruídos pelo próprio político reeleito, ou pelo seu sucessor do mesmo partido (ou de uma coalizão), e não por um candidato de oposição. Por outro lado, esses mesmos benefícios devem ser vistos com certo ceticismo, pois os policymakers devem considerar os efeitos negativos futuros de suas próprias políticas (inflação/desemprego).

As teorias dos ciclos políticos focam suas atenções nas decisões (econômicas e/ou políticas) a serem tomadas pelos governantes de forma a induzir sua permanência no poder, manipulando instrumentos de política econômica e/ou fiscal, com fins de promoção pessoal e/ou partidária. Considerando-se, porém, que o governo - nas suas funções alocativa, distributiva e estabilizadora - existe para atender as demandas da coletividade e para proporcionar o bem-estar social da população em geral, os programas governamentais não deveriam ser afetados por tal política. No entanto, apesar do grande espaço de manobra do governante, esse incentivo à distorção fiscal pode ser reduzido por diversos aspectos. 0 primeiro, e mais natural, é a impossibilidade de reeleição do titular, que tem um número de mandatos limitado pelas constituições da maioria dos países democráticos. De acordo com Meneguin e Bugarin (2003, p. 4):

É inegável que um governante prefere que seu partido continue no poder; entretanto, seu estímulo no sentido de induzir essa reeleição do partido é bem menor do que aquele de induzir sua própria reeleição, sobretudo quando o candidato do partido adota uma postura política de crítica ao governante titular. Há ainda que se considerar o efeito das pesquisas de opinião no comportamento do titular. 
O objetivo do presente trabalho é analisar o comportamento dos gastos municipais fluminenses, entre 1998 e 2006, a fim de detectar eventuais "comportamentos cíclicos" nos gastos públicos e suas inter-relações com o calendário eleitoral.

O trabalho está organizado em cinco seções. Na segunda seção, que se segue a esta introdução, discorre-se sobre o arcabouço teórico que envolve tema, em especial os modelos que procuram explicar a associação entre econômicos e questões políticas. Em seguida, a terceira seção aborda a metodologia que guiou a pesquisa. Na quarta seção analisam-se os resultados encontrados, para depois apresentar, na quinta e última seção, algumas conclusões e considerações finais.

\section{REFERENCIAL TEÓRICO}

Nesta seção discorre-se sobre os fundamentos conceituais do trabalho. Depois de breve recordação sobre conceitos básicos de Contabilidade Pública (\$2.1), em § 2.2 são apresentados os principais aspectos da chamada teoria dos ciclos político-econômicos (ver, por exemplo, Frey e Schneider, 1975, 1978, 1981; Frey, 1997).

\subsection{A CONTABILIDADE E O ORÇAMENTO PÚBLICOS}

Orçamento público é o ato administrativo do Poder Executivo - revestido de força legal por ser autorizado pelo Poder Legislativo - que estabelece um conjunto de ações governamentais a serem realizadas durante determinado período de tempo. É na Lei Orçamentária Anual que são estimados os recursos a serem arrecadados (receitas), bem como fixados o montante das despesas a serem executadas para atender às necessidades da população, além de permitir o desenvolvimento das atividades da máquina administrativa.

A contabilidade orçamentária controla as receitas estimadas e realizadas e as despesas previstas e executadas, evidenciando a origem dos recursos e também sua forma de aplicação. Através da análise do orçamento é possível diagnosticar se os recursos são provenientes da atividade normal ao ente público ou se ele está se endividando ou vendendo bens para conseguir recursos e também avaliar o montante aplicado na manutenção dos serviços públicos e na formação do patrimônio público. Para isso, as receitas e despesas são classificadas em duas categorias econômicas - corrente e de capital.

Despesa pública, conforme Baleeiro (1988, p. 81) é “a aplicação de certa quantia, em dinheiro, por parte da autoridade ou agente público competente, dentro de uma autorização legislativa, visando a execução de determinada atividade a cargo do governo". Assim, as despesas públicas representam todo desembolso financeiro realizado pelo Estado, os quais devem gerar a satisfação das necessidades apresentadas pela sociedade (saúde, habitação, educação, segurança pública) através do fornecimento de bens e serviços, bem como suprir o próprio Estado, capacitando-o para executar suas atividades diversas (política, administrativa, financeira). Para toda e qualquer despesa que integra os orçamentos, suas formas de financiamento devem ser indicadas, sejam elas as receitas típicas do poder público (por exemplo, o recolhimento de tributos), ou outras fontes de financiamento, tais como os empréstimos, conforme os limites impostos pelo artigo $167 \mathrm{da}$ Constituição Federal de 1988 (CF/88).

As receitas públicas, de acordo com Silva (2004, p. 103), podem ser classificadas em diversos aspectos: quanto à natureza, quanto ao poder de tributar, quanto à 
coercitividade, quanto à afetação patrimonial, quanto à regularidade. As receitas classificadas como Orçamentárias englobam todas as receitas, inclusive operações de crédito autorizadas em lei, excetuadas as extraorçamentárias, as quais são apenas ingresso financeiro de caráter temporário, pois pertencem a terceiros e o Estado atua como simples depositário.

0 ativo financeiro compreende créditos, valores realizáveis e valores numerários que podem ser movimentados independentemente de autorização legislativa, tais como dinheiro em tesouraria, depósito bancário, aplicações financeiras e devedores diversos. 0 passivo financeiro abrange os compromissos exigíveis, provenientes de operações que devam ser pagas independentemente de autorização orçamentária, tais como restos a pagar, serviço da dívida a pagar, depósitos de diversas origens, consignações e débitos de tesouraria. Portanto, o resultado financeiro (déficit ou superávit) é a diferença entre o ativo e o passivo financeiros, apurados no balanço patrimonial do exercício anterior, conjugando-se ainda os saldos dos créditos adicionais transferidos e as operações de créditos a eles vinculados.

De acordo com a Lei 4320/64, os créditos da Fazenda Pública, de natureza tributária ou não, exigíveis pelo transcurso do prazo para pagamento, serão inscritos, na forma da legislação própria, como Dívida Ativa, em registro próprio, após apurada sua liquidez e certeza, e a respectiva receita será escriturada a esse título. Dívida Ativa tributária é o crédito da Fazenda Pública dessa natureza, proveniente de obrigação legal relativa a tributos e respectivos adicionais e multas, enquanto que a Dívida Ativa nãotributária se refere aos demais créditos da Fazenda Pública como, por exemplo, as contribuições estabelecidas em lei ou os foros e laudêmios, bem como os créditos decorrentes de obrigações em moeda estrangeira, de sub-rogação de hipoteca, fiança, aval ou outra garantia, de contratos em geral ou de outras obrigações legais.

Ainda de acordo com a referida Lei, em seu art. 36, consideram-se Restos a Pagar as despesas empenhadas, mas não pagas até o dia 31 de dezembro, distinguindo-se as processadas (compromissos que, ao terminar o exercício financeiro, já estavam em processo de pagamento) das não-processadas (os provenientes de despesa simplesmente empenhada, ou seja, compromissos, cujo processo de pagamento não tenha sido finalizado, inclusive pelo não-cumprimento do estágio de liquidação da despesa). Os empenhos que correm à conta de créditos com vigência plurianual, que não tenham sido liquidados, só serão computados como Restos a Pagar no último ano de vigência do crédito.

\subsection{MODELOS DE CICLOS POLÍTICO-ECONÔMICOS}

De longa tradição intelectual e acadêmica (ver, por exemplo, a abrangente resenha de Salvato et al., 2007), a literatura sobre os ciclos político-econômicos procura analisar de que forma a ideologia dos governantes e seu desejo de serem reeleitos influenciam a evolução da economia. Atribui-se a Nordhaus (1975) um dos primeiros modelos sobre essa temática, em que "políticos oportunistas" estimulam a economia às vésperas dos escrutínios de forma a aumentarem a sua probabilidade de reeleição e, após as eleições, eliminam a inflação que resulta deste comportamento provocando uma recessão. Para Veiga e Veiga (2004, p. 4), este modelo pressupõe expectativas adaptativas (mas ainda não expectativas racionais), o que permite aos governantes escolherem a combinação preferida (pelos eleitores) entre inflação e desemprego ao longo da curva de Philips, enganando sistematicamente o eleitorado antes das eleições. Neste sentido, segundo Nordhaus, os eleitores são considerados "míopes" e retrospectivos, pois teriam memória curta em relação a questões macroeconômicas, tomando suas decisões com base no passado. Graficamente, como se pode visualizar no gráfico 1, a desutilidade marginal do desemprego, para o eleitor, é maior que a desutilidade marginal da inflação. 
Questionando a abordagem sugerida por Nordhaus, o trabalho de Hibbs (1977) incorpora a variável "ideologia partidária", considerando que os partidos políticos querem se manter no poder e implementar suas ideologias. Em outras palavras, e valendo-se também do instrumental da curva de Philips, esse autor considerou que cada partido político tentará implementar políticas que visem beneficiar aquele determinado grupo de eleitores que o apoiou. Desta forma, conforme o gráfico 2, os partidos "de direita" (ligados a classes mais abastadas) teriam maior aversão à inflação, enquanto que os partidos "de esquerda" (ligados a classes mais desfavorecidas) teriam maior preocupação com o combate ao desemprego, sem negar a importância de ambas as variáveis para os partidos. Portanto, um partido de direita tende a deslocar-se para a direita da curva de Philips (reduzindo a taxa de inflação, mas aumentado a taxa de desemprego - ponto C); mutatis mutandis para os partidos de esquerda (ponto B). Portanto, na proposta considerada em Hibbs (1977), os políticos, uma vez no poder, tentam favorecer os grupos da população que os elegeram, o que os leva a ter objetivos diferentes (partidos de esquerda versus partidos de direita) quanto à evolução das variáveis econômicas.

\section{Gráfico 1}

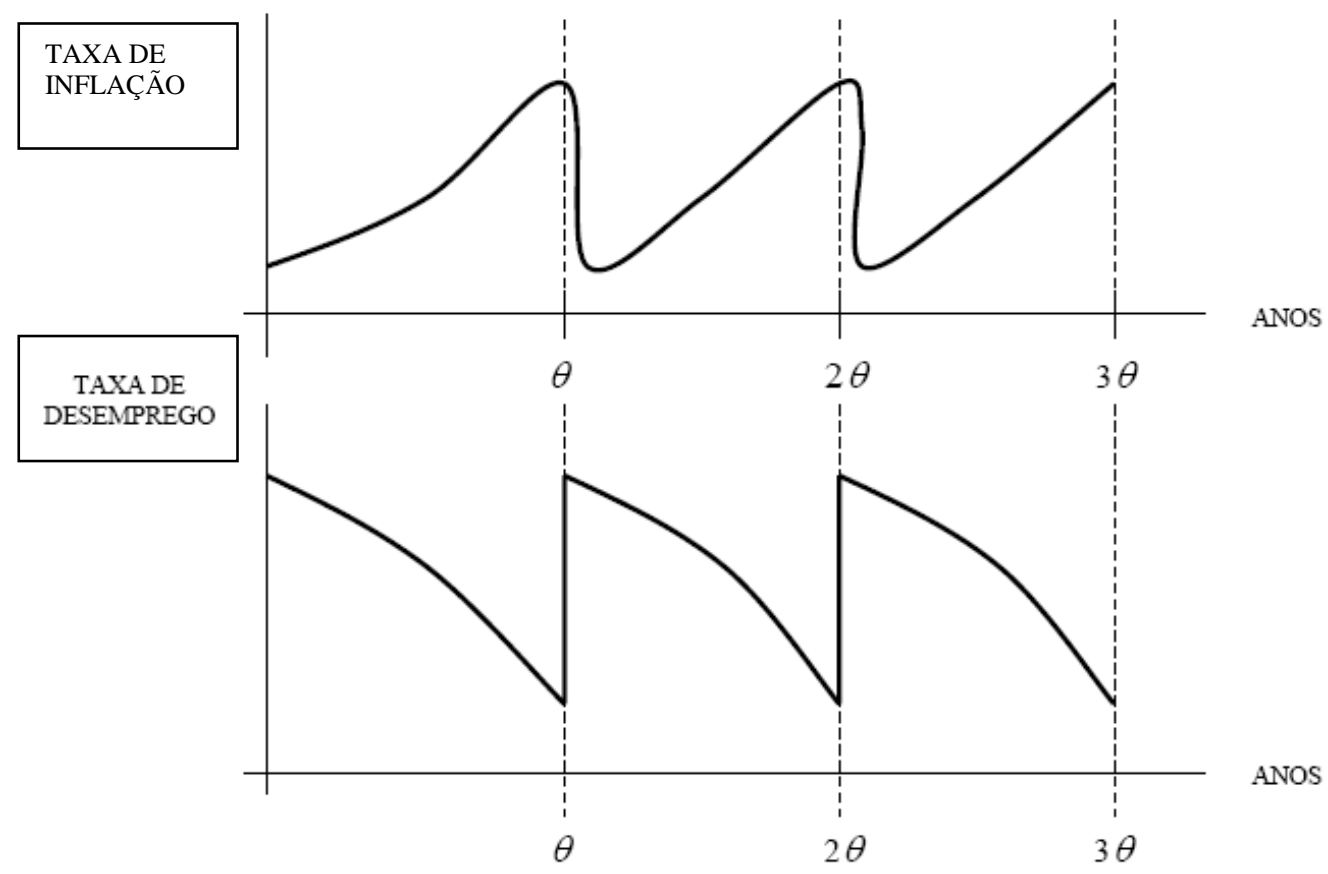

Fonte: Preussler e Portugal (2002) 


\section{Gráfico 2}

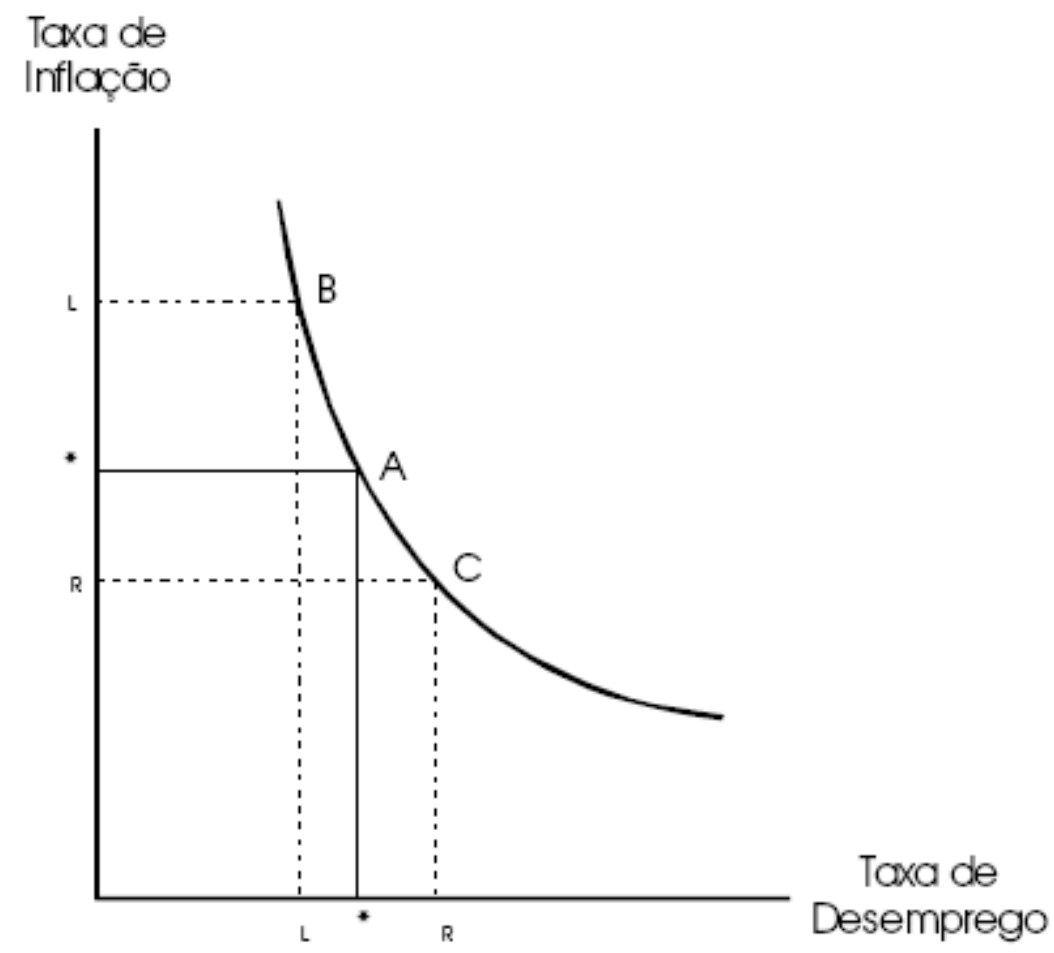

Fonte: Cançado e Araújo Jr (2004)

A evolução da consciência do eleitorado exigiu a reformulação do modelo de Nordhaus, tendo surgido diversos trabalhos que procuram conciliar a hipótese de políticos oportunistas com a hipótese de eleitores racionais. Estes trabalhos supõem que, embora todos os governos sejam oportunistas, eles diferem em termos de seu nível de competência. No entanto, os eleitores só conseguem determinar a competência dos governos depois de observarem os resultados econômicos das políticas por estes implementadas em seu mandato. Desta forma, na véspera das eleições, governantes oportunistas aproveitam-se dessa assimetria de informação, procurando sinalizar um elevado grau de competência ao eleitorado, dando origem, então, ao ciclo políticoeconômico.

Entre os modelos racionais de oportunismo destacam-se os trabalhos de Rogoff e Sibert (1988) e Rogoff (1990), segundo os quais, sendo a política orçamentária um tema de grande complexidade para a maioria dos eleitores, é de esperar que seja utilizada pelos governantes para sinalizarem sua competência. Em Rogoff e Sibert (1988) supõe-se que o governo deva providenciar um montante fixo e observável de bens públicos, sendo a competência avaliada pelo montante de impostos que terão de cobrar para fornecê-los. Os autores demonstram que todos os governantes, exceto os menos competentes, aumentam os impostos de forma distorcida na véspera das eleições para transparecerem sua competência. No modelo de Rogoff (1990), que enfatiza a composição das despesas públicas em vez das receitas, os governantes sinalizam a competência aumentando as despesas públicas em bens e serviços e em transferências, e diminuindo o investimento público, uma vez que este último apenas se torna visível em períodos posteriores.

As expectativas racionais, de longa tradição na literatura econômica, foram introduzidas no modelo de ideologia por Alesina (1987). De acordo com este autor, a incerteza quanto à ideologia do partido que ganhará as eleições poderá originar erros nas 
expectativas de inflação para o período imediatamente pós-eleitoral. Desta forma, tornarse-á possível aos governantes, em função de sua ideologia, desviar a taxa de desemprego de seu valor natural imediatamente após as eleições.

Apesar de a literatura internacional sobre ciclos político-econômicos já ser, hoje, bastante extensa, a maioria dos trabalhos empíricos analisa o comportamento dos governos centrais. No entanto, desde o início da década de 1990 Rogoff (1990) havia destacado o interesse de investigar o poder público local. Segundo esse autor, os testes empíricos referentes à existência de ciclos eleitorais deveriam centrar-se nos instrumentos de políticas orçamentárias, tendo em vista ser mais fácil aos governantes manipularem o orçamento do que os agregados macroeconômicos. Afirmou, ainda, que para variáveis tais como os impostos e os gastos, seria possível obter dados referentes aos governos locais, com a vantagem de obter, ao mesmo tempo, um número muito maior de observações do que em análises agregadas. No mesmo ano, Kalchheim e Rozevitch (1990) estudaram a relação entre déficit orçamentário e eleições parlamentares e municipais em Israel. Segundo esses autores, neste país era usual a ocorrência de déficits em três níveis de governo - municipal, local e regional.

O quadro 1 resume as quatro vertentes dos ciclos políticos, bem como seus principais referenciais teóricos, até aqui analisados. De um lado a dicotomia dos eleitores (agentes econômicos) e suas expectativas; de outro, a dicotomia dos policymakers e seus partidos.

$\mathrm{Na}$ literatura, os benefícios que provêm da manipulação "eleitoreira" são enfatizados pelos chamados modelos de ciclos políticos oportunísticos, enquanto que os custos são enfatizados pelos modelos de controle eleitoral, conforme classificação sugerida por Meneguin e Bugarin (2001). Estes autores propuseram um modelo segundo o qual um governante tende a maximizar suas ações dentro de um mandato, sem se preocupar com os efeitos futuros, caso não vislumbre a possibilidade de reeleição. Assim, nos casos em que não há reeleição, o déficit do governante que está deixando o mandato é elevado, passando a ser do seu sucessor, portanto, a preocupação com os serviços da dívida. Sob a ótica de tais considerações, a reeleição incentivaria os governantes ao não endividamento excessivo, sendo o conservadorismo na política fiscal diretamente proporcional à possibilidade de reeleição. Na verdade, Meneguin e Bugarin (2001) e Nakaguma (2006) defendem a reeleição como uma forma de contenção de gastos.

Quadro 1

\begin{tabular}{|l|l|c|c|}
\hline & & & \multicolumn{2}{|c|}{ PARTIDOS } & IDEOLÓGICOS \\
\hline & & OPORTUNISTAS & Teoria partidária \\
\hline \multirow{3}{*}{ ELEITORES } & & Teoria oportunista & Hibbs \\
\cline { 2 - 4 } & TRADICIONAIS & Nordhaus & Frey e Lau \\
\cline { 2 - 4 } & & Lindbeck & Teoria partidária racional \\
\hline \multirow{3}{*}{} & & Teoria oportunista racional & Alesina \\
\hline & RACIONAIS & Rogoff e Sibert & Alesina e Sachs \\
\hline
\end{tabular}

Fonte: adaptado de Martins (2002)

O aumento da consciência do eleitorado, a partir da própria exposição a um número mais elevado de alternativas políticas, permite que seja avaliada de maneira cada vez mais rigorosa tanto a própria oferta política, quanto a gestão dos governos no poder. Além 
disso, neste contexto de competição política, a manutenção de práticas de manipulação eleitoral fica limitada. Este perfil de eleitor mais consciente acaba impondo certa disciplina aos gastos públicos.

\section{METODOLOGIA}

A pergunta de pesquisa que se pretende responder é: no que se refere ao caso dos municípios fluminenses, existem evidências de "manipulações cíclicas" no comportamento administrativo dos prefeitos entre 1998 e 2006, especialmente nos anos eleitorais?

Uma hipótese de pesquisa que constitua uma resposta temporária - até que seja testada e comprovada - a essa pergunta pode ser obtida na chamada teoria dos ciclos políticos (Frey e Schneider, 1975; Nordhaus, 1975) em sua forma modificada tal como argumentaram Drazen (2001), Shi e Svensson (2003, 2006), ou Vergne (2009). Esta modificação consiste basicamente em alterar o alvo da influência dos ciclos: em vez de focalizar a influência sobre variáveis de natureza mais macroeconômica (tais como o crescimento do PIB ou a evolução do emprego), aqueles autores examinaram o efeito sobre diferentes instrumentos de política pública, especialmente os mais utilizados pelos public policymakers (VERGNE, 2009, p. 63, nota 1). Por exemplo, Vergne (Id.) investigou os budget political cycles. Com apoio nessa argumentação e seguindo o exemplo pioneiro de Meneguin e Bugarin (2001) e Ferreira e Bugarin (2006), a hipótese de pesquisa a ser testada neste trabalho pode ser enunciada como: no que se refere ao caso dos municípios fluminenses, a ocorrência de eleições para mandatos em qualquer nível de governo afeta as variáveis fiscais e contábeis que representam a evolução das contas públicas municipais.

0 objetivo de analisar o efeito do calendário eleitoral sobre variáveis contábeis municipais não recomenda nem a utilização exclusiva de dados em corte transversal (cross section), nem de dados de séries temporais, ainda mais por que o tamanho da amostra era de apenas 40 observações para cada um dos nove anos do período. Ao proceder à análise empírica dessas questões utilizou-se então a metodologia de dados em painel (panel data), que combina aqueles dois tipos de dados.

A especificação econométrica escolhida foi o modelo de efeitos fixos ou de pooling com variáveis dummies (Judge et al., 1985, p. 519-521), permitindo que a estimação fosse feita pelo programa SPSS - Statistical Package for the Social Sciences (versão 12.0). A principal consequência da adoção do modelo de efeitos fixos é que as inferências sugeridas pelo exercício estão condicionadas à amostra (Judge et al., 1985, p. 527), no caso presente aos municípios selecionados. Ademais, seguindo Avellaneda (2008, p. 19), uma vantagem desse modelo é capturar efeitos capazes de distinguir entre os municípios, mas que não foram diretamente observados ou mensurados através das variáveis independentes presentes nas equações. Além disso a autora relembra que, ao contrário do modelo com efeitos aleatórios, com efeitos fixos não é preciso impor sua correlação nula com as variáveis independentes (Avellaneda, 2008, p. 19, nota 24). Em resumo, ao aceitar a limitação da inferência condicional à amostra, a adoção do modelo de efeitos fixos dispensa a aplicação preliminar do teste de Hausman (cf. Sakurai, 2004; Sakurai e Gremaud, 2007, p. 33).

Estudos anteriores (por exemplo, Schuknecht, 2000; Milesi-Ferretti, Perotti e Rostagno, 2002; Shi e Svensson, 2003; Vergne, 2009) mostraram como as decisões dos governantes são afetadas pela possibilidade de permanência no governo, em especial as decisões referentes aos gastos públicos. Pode-se verificar esse impacto por meio de uma regressão em que se estude o grau de associação linear entre os dispêndios realizados pelo 
governante em anos eleitorais e o fato de ter conseguido reeleger-se ou não. No presente estudo, apesar de não haver qualquer dificuldade técnica para aplicar este tipo de análise de regressão, não foi possível encontrar uma equação satisfatória que, submetida aos dados empíricos, incluísse, ao mesmo tempo, a dummy de reeleição e as demais variáveis recomendadas na literatura.

No presente trabalho foram estimadas equações de regressão múltipla correspondendo a diversas variáveis dependentes, a saber (a) pelo lado da despesa: despesa orçamentária, corrente, com pessoal e encargos, de investimento; e (b) pelo lado da receita: receita orçamentária, outras transferências da União, outras transferências do Estado. Além destas, também foram incluídas como dependentes as despesas por função, categorizadas agregadamente como: legislativa, agricultura, transporte, educação e cultura, habitação e urbanismo, saúde e saneamento, e assistência e previdência. A variável receita orçamentária também foi utilizada como variável explicativa visto que os possíveis impulsos de despesas realizados pelos policymakers podem ser explicados pelo aumento no volume de arrecadação.

A forma funcional proposta a seguir se assemelha às utilizadas em Petterson-Lidbom (2001), que analisou 288 municípios suecos entre os anos de 1974 e 1988, e em Sakurai (2004) e Sakurai e Gremaud (2007), que analisaram o comportamento fiscal de 572 municípios do Estado de São Paulo entre os anos de 1989 e 2001, utilizando também a metodologia de dados em painel.

Como o objetivo principal desse trabalho é encontrar evidências de ciclos políticos no comportamento dos prefeitos fluminenses, especificou-se a seguinte forma funcional:

$$
\begin{aligned}
\text { VD }_{i t}= & B_{0}+B_{1} \cdot \text { RECORCA }_{i t}+B_{2} \cdot \text { SUPERFIN }_{i t} \\
& +B_{3} \cdot \text { PDT }_{i t}+B_{4} \cdot \text { PSDB }_{i t}+B_{5} \cdot \text { PFL }_{i t}+B_{6} \cdot \text { PP }_{i t}+B_{7} \cdot \text { PSB }_{i t} \\
& +B_{8} \cdot \text { OUT_PARTIDO }_{i t}+B_{9} \cdot \text { PARTID_ESQ }_{i t} \\
& +B_{10} \cdot \text { MESMODOGOV }_{i t}+B_{11} \cdot \text { MESMODOPRESID }_{i t} \\
& + \text { dummies de ano }+f_{i}+u_{i t},
\end{aligned}
$$

em que VD representa cada variável dependente analisada, RECORCA é a receita orçamentária municipal, e SUPERFIN é o resultado financeiro, podendo ser superávit ou déficit financeiro.

As variáveis dummies dos partidos analisados assumem valor igual a 1 se o prefeito for daquele partido (p. ex., PDT, PSDB, PFL) e 0 nos demais casos. A variável OUT_PARTIDO representa o conjunto dos outros partidos da amostra, que foram agrupados nesta variável, enquanto que PARTID_ESQ é uma variável dummy que assume valor igual a 1 caso o prefeito seja de um partido considerado "de esquerda" e 0 em caso contrário. A classificação partidária em "direita" ou "esquerda" foi utilizada em consonância com Carreirão (2006) em seu estudo sobre o caso do estado de Santa Catarina. No entanto, para usar apenas uma dicotomia, os partidos PMDB e PSDB, que foram classificados por aquele autor como sendo de "centro", foram classificados, no presente estudo, como sendo de "direita" (na verdade, não-esquerda). Além disso, em alguns casos, foram consultados os sites dos próprios partidos para dirimir possíveis dúvidas. A variável MESMODOGOV é uma variável dummy que assume valor igual a 1 caso haja coincidência partidária entre o prefeito e o governador e 0 em caso contrário, sendo análoga a definição de MESMODOPRESID, que assume, então, valor igual a 1 caso haja coincidência partidária entre o prefeito e o presidente e 0 em caso contrário. 
As variáveis denominadas dummies de ano representam cada ano do período analisado (exceto o ano de referência, escolhido como 1998), enquanto que $f_{i}$ é o efeito fixo relativo ao i-ésimo município e $\mathrm{U}_{\text {it }}$ é o erro aleatório. $O$ subscrito i designa cada município da amostra e t, cada ano da amostra. Vale notar que o efeito fixo varia entre municípios, mas é constante ao longo do tempo.

A fonte de dados para a análise empírica é o banco de dados disponibilizado pela Secretaria do Tesouro Nacional (STN) que trata das Finanças do Brasil - Receitas e Despesas dos Municípios (FINBRA). Foram incluídos no estudo apenas os 40 municípios para os quais não faltava nenhuma informação naquele banco de dados. Assim, é possível que, se a eliminação tivesse sido menos seletiva, a amostra final teria sido um pouco maior. Além disso, considerando que a existência de informações deve depender dos recursos municipais, pode ter ocorrido algum viés de seleção (selection bias) favorecendo a presença de municípios "mais ricos" e fazendo com que as inferências sugeridas pelo exercício estejam condicionadas à amostra.

Em todas as equações os valores correntes foram transformados em valores reais de 2006 por meio do deflator implícito do PIB. Finalmente, as variáveis fiscais foram transformadas para valores per capita a fim de corrigir eventuais distorções nos resultados devido a diferenças de "tamanho" entre os municípios. Esta providência também se coaduna com a hipótese de efeitos fixos e com alguma atenuação da hipótese de heteroscedasticidade.

\section{RESULTADOS}

Nesta seção são apresentados e analisados os resultados obtidos no exercício empírico. No total são relatados os resultados correspondentes a quatorze equações estimadas, resumidos em quatro tabelas. Cada subseção diz respeito a uma escolha da variável dependente, mas na subseção $\$ 4.6$ as despesas por função estão apresentadas em conjunto.

No texto, a menção à significância estatística se refere ao nível de significância de $10 \%$ ou menos, tanto para o teste t de Student (relativo à significância individual de cada variável presente na equação), quanto para o teste $F$ de Fisher-Snedecor (para a significância simultânea das variáveis, ou, o que é o mesmo, para a significância da equação). Nas tabelas, conforme está alertado em nota explicativa, a significância é abreviadamente indicada por asteriscos, segundo o nível obtido ( $1 \%, 5 \%$ ou $10 \%)$, quando coube.

Finalmente, merece um último comentário liminar o fato de que os critérios usuais (tais como correlação bivariada e valor do condition index) não indicaram ocorrência severa de multicolinearidade (GUJARATI, 1988, p. 301).

Por comodidade de exposição, nem sempre se vai reiterar que as unidades monetárias devem ser consideradas em valores reais per capita.

\subsection{DESPESA ORÇAMENTÁRIA}

Este item da despesa refere-se à totalidade das despesas municipais. Os resultados (ver tabela 1) sugerem que para cada $\mathrm{R} \$ 1,00$ de receita arrecadada pelos municípios, os governantes gastam R\$ 1,03 evidenciando um ligeiro déficit orçamentário. Já em relação ao superávit financeiro, observa-se uma relação inversa (como era de esperar), ou seja, para cada $\mathrm{R} \$ 1,00$ de caixa economizado, as despesas diminuem $\mathrm{R} \$ 0,30$. 
Não foram encontradas evidências significativas de ciclos políticos neste item agregado da despesa, à exceção de uma redução significativa dos gastos em 2005 mostrando um provável ajuste de gastos em relação ao ano eleitoral de 2004. Para as dummies de partido, também não foram encontradas evidências significativas que indicassem alguma distinção no comportamento ideológico-partidário em relação ao PMDB. A coincidência partidária entre os prefeitos e o presidente apresenta relação inversa semelhante ao resultado encontrado em Cossio (2001) para os estados brasileiros - ou seja, pertencer ao mesmo partido do presidente significa redução dos gastos municipais, indicando uma espécie de "pacto de ajuste fiscal" entre os níveis de governo.

Tabela 1. Resultado das Regressões - Método de Efeitos Fixos

\begin{tabular}{|c|c|c|c|c|}
\hline VARIÁVEL & $\begin{array}{c}\text { DESPESA } \\
\text { ORÇAMENTÁRIA }\end{array}$ & $\begin{array}{c}\text { DESPESA } \\
\text { CORRENTE }\end{array}$ & $\begin{array}{l}\text { DESPESA } \\
\text { PESSOAL }\end{array}$ & $\begin{array}{c}\text { DESPESA } \\
\text { INVESTIMENTO }\end{array}$ \\
\hline CONSTANTE & $-72,221$ & $134,957 * * *$ & $388,439 *$ & $-207,769 *$ \\
\hline PREF_PDT & $-41,446$ & $250,750 *$ & $-2,200$ & $-270,241 *$ \\
\hline PREF_PSDB & $96,698 * * *$ & 25,924 & 37,904 & 77,285 \\
\hline PREF_PFL & $-39,783$ & $-25,503$ & $-26,485$ & $-13,985$ \\
\hline PREF_PP & $-28,143$ & $-49,014$ & $-26,975$ & 22,638 \\
\hline PREF_PSB & $-49,742$ & $213,585^{*}$ & 12,660 & $-236,420 *$ \\
\hline OUTROS PARTIDOS & $-26,063$ & $205,468 *$ & $-13,896$ & $-203,308 *$ \\
\hline PARTIDOS DE ESQUERDA & 23,060 & $-245,382 *$ & $-34,207$ & $247,858^{*}$ \\
\hline PARTIDO PREF. = GOVERN. & $-21,292$ & $-11,684$ & $-14,200$ & $-6,917$ \\
\hline PARTIDO PREF. =PRESID. & $-134,701 *$ & $-69,181$ & $-40,599$ & $-62,467$ \\
\hline DUM_1999 & $-37,423$ & 12,926 & $-11,505$ & $-46,573$ \\
\hline DUM_2000 & $-68,062 * *$ & $-2,041$ & $-18,101$ & $-49,654$ \\
\hline DUM_2001 & $-64,049 * *$ & 9,108 & 21,353 & $-63,896 * * *$ \\
\hline DUM_2002 & $-53,120 * * *$ & $-59,509$ & $58,352 * *$ & 18,682 \\
\hline DUM_2003 & $-26,786$ & 32,576 & $94,222 *$ & $-47,222$ \\
\hline DUM_2004 & $-52,704 * * *$ & 16,704 & $101,675^{*}$ & $-53,013$ \\
\hline DUM_2005 & $-75,521 * *$ & 55,782 & $70,975 *$ & $-126,568 *$ \\
\hline DUM_2006 & $-21,510$ & $126,059 *$ & $105,066^{*}$ & $-144,956 *$ \\
\hline REC. ORCAMENTARIA & $1,032 *$ & $0,767 *$ & $0,242 *$ & $0,248 *$ \\
\hline RESULTADO FINANCEIRO & $-0,297 *$ & $-0,220 *$ & $-0,066^{* *} *$ & $-0,053$ \\
\hline $\mathrm{R}^{2}$ ajust & 0,989 & 0,972 & 0,946 & 0,802 \\
\hline ESTATÍSTICA - F & 579,668 & 156,139 & 108,696 & 26,137 \\
\hline
\end{tabular}

*, ${ }^{* *},{ }^{* * *}$ - Significância ao nível de $1 \%, 5 \%$ e $10 \%$ respectivamente. No teste $F$, para todas as variáveis o $\mathrm{p}$-valor $<0,001$

\subsection{DESPESA CORRENTE}

Este item da despesa refere-se aos gastos para manutenção e funcionamento dos serviços públicos em geral. Os resultados (ver tabela 1 ) sugerem que para cada $R \$ 1,00$ de receita arrecadada pelos municípios, os governantes gastam $\mathrm{R} \$ 0,77$ em despesa corrente. Em relação ao superávit financeiro pode-se dizer que a relação foi inversa (como era de esperar), ou seja, para cada $\mathrm{R} \$ 1,00$ de caixa economizado, as despesas correntes diminuem $\mathrm{R} \$ 0,22$. Foram encontradas evidências estatisticamente significativas de "manipulação eleitoral" neste item da despesa, mais especificamente uma elevação significativa em 2006, um ano de eleições para Presidente, Governador e para o Congresso Nacional.

Para as dummies de partido, foram obtidos resultados estatisticamente significativos para o PDT, PSB e para o agregado "Outros Partidos", cujos gastos são em média superiores ao PMDB em $\mathrm{R} \$ 250,75$, $\mathrm{R} \$ 213,59$ e $\mathrm{R} \$ 205,47$ per capita 
respectivamente. Para os demais partidos não foram encontradas evidências significativas que indicassem alguma distinção no comportamento ideológico-partidário em relação ao PMDB. Entretanto - inclusive de forma anti-intuitiva (já que o PDT e o PSB são partidos de esquerda) - os partidos de esquerda gastam menos ( $R \$ 245,38$ per capita) que os partidos de direita neste item da despesa.

\subsection{DESPESA DE PESSOAL E ENCARGOS}

Nesta categoria, os resultados (ver tabela 1 ) sugerem que para cada $R \$ 1,00$ de receita arrecadada pelos municípios, os governantes gastam $\mathrm{R} \$ 0,24$ em despesa com pessoal. No caso do superávit financeiro, ocorreu uma relação inversa (como era esperado), ou seja, para cada $\mathrm{R} \$ 1,00$ de caixa economizado, as despesas com pessoal diminuem R\$ 0,07. De acordo com a tabela de regressão, pode-se observar uma elevação significativa deste item da despesa no ano de 2003. Pode-se inferir, também, que há evidências significativas de impulsos positivos neste item da despesa para os anos de 2004 e 2006 em relação aos anos imediatamente anteriores e posteriores (ou apenas anteriores, no caso de 2006, pois não foram coletados dados para 2007).

Não foram encontradas evidências significativas que indicassem alguma distinção no comportamento ideológico-partidário, neste item da despesa, em relação ao PMDB.

\subsection{DESPESA DE INVESTIMENTO}

Os resultados (ver tabela 1 ) para o investimento indicam que para cada $\mathrm{R} \$ 1,00$ de receita arrecadada pelos municípios, os governantes investem $\mathrm{R} \$ 0,25$. Foi possível encontrar evidências estatisticamente significativas neste item da despesa, mais especificamente uma redução nos anos de 2005 e 2006, mostrando um provável ajuste de gastos em relação ao ano eleitoral de 2004.

Para as dummies de partido, são obtidos resultados estatisticamente significativos para o PDT, PSB e para o agregado "Outros Partidos", cujos gastos são em média inferiores ao PMDB em R\$270,24, R\$236,42 e R\$203,31 per capita respectivamente. Para os demais partidos não foram encontradas evidências significativas que indicassem alguma distinção no comportamento ideológico-partidário em relação ao PMDB. Entretanto - inclusive de forma contra-intuitiva (já que o PDT e o PSB são partidos de esquerda) - os partidos de esquerda gastam mais ( $\mathrm{R} \$ 247,86$ per capita) que os partidos de direita neste item da despesa.

\subsection{RESULTADO FINANCEIRO}

Este item é apurado no balanço patrimonial e, para fins deste trabalho, corresponde à diferença entre o ativo e o passivo financeiros. Como bem salienta Silva (2003), também são incluídos no cálculo os saldos dos créditos adicionais transferidos e as operações de crédito a eles vinculadas. Os resultados (ver tabela 2) mostram que para cada $\mathrm{R} \$ 1,00$ de receita arrecadada pelos municípios, os governantes economizam em caixa $\mathrm{R} \$ 0,10$.

Foram encontradas elevações significativas no ano de 2001, provavelmente para servirem de fonte de abertura de créditos adicionais no ano de 2002. Em contrapartida ocorreu uma redução significativa em 2003, mantendo-se, entretanto, o superávit financeiro (pode estar associado à elevação significativa para a despesa com pessoal e encargos observada no mesmo ano). Não foram encontradas evidências significativas que indicassem alguma distinção no comportamento ideológico-partidário em relação ao PMDB. 
Tabela 2. Resultado das Regressões - Método de Efeitos Fixos

\begin{tabular}{|c|c|c|c|}
\hline VARIÁVEL & RESULTADO FINANCEIRO & RESTOS A PAGAR & DÍVIDA ATIVA \\
\hline CONSTANTE & $-231,829^{*}$ & $135,200^{*}$ & $1252,183^{*}$ \\
\hline PREF_PDT & $-43,169$ & 26,044 & 90,316 \\
\hline PREF_PSDB & $-52,458$ & $-72,995^{*}$ & 46,434 \\
\hline PREF_PFL & $-116,845^{* * *}$ & $-24,274$ & $-73,253$ \\
\hline PREF_PP & $-21,699$ & $-46,539^{* *}$ & 62,743 \\
\hline PREF_PSB & $-16,562$ & 17,019 & $211,272^{*}$ \\
\hline OUTROS PARTIDOS & $-97,802$ & 7,756 & 7,002 \\
\hline PARTIDOS DE ESQUERDA & $-102,002$ & $-37,905$ & $-132,947^{* *}$ \\
\hline PARTIDO PREF. = GOVERN. & $-4,686$ & $-5,512$ & $-15,249$ \\
\hline PARTIDO PREF. =PRESID. & 70,987 & 0,461 & 69,326 \\
\hline DUM_1999 & 20,799 & $-16,853$ & 26,553 \\
\hline DUM_2000 & $75,693^{* * *}$ & $-47,998^{*}$ & 40,118 \\
\hline DUM_2001 & $183,955^{*}$ & $-60,794^{*}$ & $121,390^{*}$ \\
\hline DUM_2002 & $192,210^{*}$ & $-61,557^{*}$ & $153,689^{*}$ \\
\hline DUM_2003 & $170,601^{*}$ & $-29,223^{* * *}$ & $162,040^{*}$ \\
\hline DUM_2004 & $208,769^{*}$ & $-83,836^{*}$ & $170,482^{*}$ \\
\hline DUM_2005 & $257,787^{*}$ & $-49,753^{*}$ & $197,145^{*}$ \\
\hline DUM_2006 & $292,058^{*}$ & $-41,461^{* *}$ & $269,720^{*}$ \\
\hline REC. ORCAMENTARIA & $0,102^{*}$ & 0,013 & 0,026 \\
\hline RESULTADO FINANCEIRO & & $-0,113^{*}$ & $-0,222^{*}$ \\
\hline R ${ }^{2}$ ajust & 0,633 & 0,407 & 0,851 \\
\hline ESTATISTICA - F & 11,869 & 5,243 & 36,433 \\
\hline & & & \\
\hline & & & \\
\hline & & & \\
\hline
\end{tabular}

*, **, *** - Significância ao nível de $1 \%, 5 \%$ e $10 \%$ respectivamente. No teste $\mathrm{F}$, para todas as variáveis o $\mathrm{p}$-valor $<0,001$.

\subsection{DESPESAS POR FUNÇÃO}

Os resultados para as despesas por função estão descritos nas tabelas 3 e 4 . Ali se pode ver que para cada $\mathrm{R} \$ 1,00$ de receita arrecadada pelos municípios, os governantes gastam $R \$ 0,03$ em agricultura, $R \$ 0,17$ em educação e cultura, $R \$ 0,03$ em previdência e assistência social, $R \$ 0,29$ em saúde e saneamento, $R \$ 0,03$ em transporte, $R \$ 0,10$ em habitação e urbanismo e R\$ 0,01 em despesas com o Legislativo. Em relação ao superávit financeiro, pode-se constatar que somente as despesas com agricultura e educação e cultura foram significativas e com sinal negativo, indicando uma relação inversa (como era de esperar), ou seja, para cada $\mathrm{R} \$ 1,00$ de caixa economizado, as despesas diminuem $\mathrm{R} \$$ 0,02 e $\mathrm{R} \$ 0,05$ respectivamente.

Observa-se uma redução significativa dos gastos em educação e cultura (tabela 3) no ano de 2002. Para os demais anos não foram encontradas evidencias significativas de ciclos políticos. Não foram encontradas evidências significativas que indicassem alguma distinção no comportamento ideológico-partidário deste item da despesa em relação ao PMDB. No que tange aos gastos com agricultura (tabela 3) não foram encontradas evidências significativas de manipulações eleitoreiras neste item da despesa. Para as dummies de partido, são obtidos resultados estatisticamente significativos para o PDT, PSB e para o agregado "Outros Partidos", cujos gastos são em média inferiores ao PMDB em R\$ 28,63 , R\$ 28,28 e $\mathrm{R} \$ 29,05$ per capita respectivamente. Para os demais partidos não foram encontradas evidências significativas que indicassem alguma distinção no comportamento ideológico-partidário em relação ao PMDB. Entretanto - e de forma inesperada (já que o 
PDT e o PSB são partidos de esquerda) - os partidos de esquerda gastam mais ( $R \$ 28,76$ per capita) que os partidos de direita neste item da despesa.

Tabela 3. Resultado das Regressões - Método de Efeitos Fixos

\begin{tabular}{|c|c|c|c|c|}
\hline VARIÁVEL & AGRICULTURA & $\begin{array}{c}\text { EDUCAÇÃO E } \\
\text { CULTRA }\end{array}$ & $\begin{array}{c}\text { ASSISTENCIA E } \\
\text { PREVIDENCIA }\end{array}$ & $\begin{array}{c}\text { SAÚDE E } \\
\text { SANEAMENTO }\end{array}$ \\
\hline CONSTANTE & $-43,317^{*}$ & $151,665^{*}$ & $-19,512$ & $-13,685$ \\
\hline PREF_PDT & $-28,629^{* *}$ & 7,764 & $-52,316^{*}$ & 28,920 \\
\hline PREF_PSDB & 5,493 & $-3,740$ & $-23,164$ & $-37,185$ \\
\hline PREF_PFL & $-10,334$ & $-10,978$ & $-2,859$ & $-4,292$ \\
\hline PREF_PP & $-0,450$ & $-1,296$ & $-6,922$ & $-38,364$ \\
\hline PREF_PSB & $-28,277^{* *}$ & 22,770 & $-63,064^{*}$ & 58,450 \\
\hline OUTROS PARTIDOS & $-29,052^{*}$ & 24,401 & $-51,313^{*}$ & 43,250 \\
\hline PARTIDOS DE ESQUERDA & $28,760^{*}$ & $-27,014$ & $50,268^{*}$ & $-17,883$ \\
\hline PARTIDO PREF. GOVERN. & $-4,199$ & $-2,318$ & $-17,262^{*}$ & $-18,739$ \\
\hline PARTIDO PREF. =PRESID. & $-4,269$ & $-19,062$ & 21,389 & $-15,181$ \\
\hline DUM_1999 & $-1,652$ & $-6,530$ & 6,408 & $-16,294$ \\
\hline DUM_2000 & $-3,282$ & 4,883 & 12,062 & $-24,951$ \\
\hline DUM_2001 & $-2,876$ & $27,095^{* *}$ & $36,980^{*}$ & $-49,984^{* *}$ \\
\hline DUM_2002 & $-5,852$ & $-35,457^{*}$ & 13,176 & $-3,951$ \\
\hline DUM_2003 & $-0,878$ & $-18,304$ & 16,701 & $-13,231$ \\
\hline DUM_2004 & $-11,559^{* * *}$ & $-21,584$ & $22,377^{* *}$ & $-21,150$ \\
\hline DUM_2005 & $-6,289$ & $-12,913$ & 18,268 & $-8,502$ \\
\hline DUM_2006 & $-14,290^{* * *}$ & 0,445 & $24,522^{* *}$ & $-3,266$ \\
\hline REC. ORCAMENTARIA & $0,034^{*}$ & $0,165^{*}$ & $0,032^{*}$ & $0,287^{*}$ \\
\hline RESULTADO FINANCEIRO & $-0,017^{* *}$ & $-0,051^{*}$ & 0,010 & $-0,042$ \\
\hline R ajust & 0,863 & 0,943 & 0,821 & 0,904 \\
\hline ESTATIISTICA - F & 39,828 & 104,122 & 29,355 & 58,964 \\
\hline
\end{tabular}

*, **, *** - Significância ao nível de $1 \%, 5 \%$ e $10 \%$ respectivamente. No teste $\mathrm{F}$, para todas as variáveis o $\mathrm{p}$-valor $<0,001$. 
Tabela 4. Resultado das Regressões - Método de Efeitos Fixos

\begin{tabular}{|c|c|c|c|}
\hline VARIÁVEL & TRANSPORTE & $\begin{array}{c}\text { HABITAÇÃO E } \\
\text { URBANISMO }\end{array}$ & $\begin{array}{c}\text { DESPESAS } \\
\text { LEGISLATIVAS }\end{array}$ \\
\hline CONSTANTE & $-24,338$ & 51,801 & $104,661^{*}$ \\
\hline PREF_PDT & $-25,376$ & $-97,172^{* *}$ & $-0,724$ \\
\hline PREF_PSDB & $-32,162^{* * *}$ & 53,537 & $-2,472$ \\
\hline PREF_PFL & $-16,295$ & $-0,723$ & $-12,003$ \\
\hline PREF_PP & 2,697 & 16,243 & $-21,947^{*}$ \\
\hline PREF_PSB & $-7,849$ & $-111,555^{*}$ & $-4,217$ \\
\hline OUTROS PARTIDOS & $-29,656^{* * *}$ & $-92,938^{*}$ & $-4,662$ \\
\hline PARTIDOS DE ESQUERDA & 19,170 & $70,898^{* *}$ & $-4,645$ \\
\hline PARTIDO PREF.= GOVERN. & $-5,823$ & 5,198 & $-2,836$ \\
\hline PARTIDO PREF.=PRESID. & $41,446^{*}$ & $-76,229^{*}$ & $-14,925^{* * *}$ \\
\hline DUM_1999 & 1,615 & $-6,904$ & 2,104 \\
\hline DUM_2000 & 9,165 & $-4,979$ & $12,078^{* *}$ \\
\hline DUM_2001 & 12,039 & 5,873 & $-15,804^{*}$ \\
\hline DUM_2002 & $-27,131^{* *}$ & 25,535 & $-22,515^{*}$ \\
\hline DUM_2003 & $-20,256^{* * *}$ & 17,686 & $-17,703^{*}$ \\
\hline DUM_2004 & $-34,859^{*}$ & 15,800 & $-22,705^{*}$ \\
\hline DUM_2005 & $-32,145^{*}$ & $-16,688$ & $-17,334^{*}$ \\
\hline DUM_2006 & $-42,197^{*}$ & 20,081 & $-12,355^{* * *}$ \\
\hline REC. ORCAMENTARIA & $0,033^{*}$ & $0,098^{*}$ & $-0,008^{*}$ \\
\hline RESULTADO FINANCEIRO & $-0,004$ & $-0,026$ & $-0,002$ \\
\hline R 2 ajust & 0,737 & 0,711 & 0,776 \\
\hline Estatística - F & 18,358 & 16,242 & 22,492 \\
\hline
\end{tabular}

*, **, *** - Significância ao nível de $1 \%, 5 \%$ e $10 \%$ respectivamente. No teste $\mathrm{F}$, para todas as variáveis o pvalor $<0,001$

De modo semelhante à análise feita para a despesa com agricultura, também para os gastos com habitação e urbanismo (tabela 4) não foram encontradas evidências significativas de ciclo eleitoral para esta rubrica. Para as dummies de partido, são obtidos resultados estatisticamente significativos para o PDT, PSB e para o agregado "Outros Partidos", cujos gastos são em média inferiores ao PMDB em R\$ 97,17, R\$ 111,56 e R\$ 92,94 per capita respectivamente. Para os demais partidos não foram encontradas evidências significativas que indicassem alguma distinção no comportamento ideológicopartidário em relação ao PMDB. Entretanto - até de forma pouco intuitiva (já que o PDT e o PSB são partidos de esquerda) - os partidos de esquerda gastam mais (R\$ 70,90 per capita) que os partidos de direita neste item da despesa. Cabe ressaltar a coincidência partidária entre o prefeito e o presidente. Neste caso, ocorreu uma relação inversa, ou seja, pertencer ao mesmo partido do presidente significa redução deste tipo de gasto.

No que tange aos gastos com previdência e assistência social (ver tabela 3), verifica-se uma significativa elevação deste item nos anos de 2001, 2004 e 2006. Portanto, os resultados sugerem evidências de ciclos políticos nas eleições para prefeito de 2004 e nas eleições para Presidente, Governador e para o Congresso Nacional em 2006. Para as dummies de partido, são obtidos resultados estatisticamente significativos para o PDT, PSB e para o agregado "Outros Partidos", cujos gastos são em média inferiores ao PMDB em R\$ 52,32 , R\$ 63,07 e R\$ 51,31 per capita respectivamente. Para os demais partidos não foram encontradas evidências significativas que indicassem alguma distinção no comportamento ideológico-partidário em relação ao PMDB. Entretanto - de forma anti-intuitiva (já que o PDT e o PSB são partidos de esquerda) - os partidos de esquerda gastam mais (R\$ 50,27 per capita) que os partidos de direita neste item da despesa. Cabe ressaltar a coincidência partidária entre o prefeito e o governador. Neste caso, observa-se uma relação inversa, ou seja, pertencer ao mesmo partido do governador significa redução deste tipo de gasto. 
Nas despesas com transporte (tabela 4), verifica-se uma redução significativa nos anos de 2002, 2004 e 2006, indicando ser este um item da despesa que sofre com o corte nos gastos em detrimento de outros de maior visibilidade eleitoral. Este e outros itens da despesa que se comportaram de modo semelhante mostram o poder das prefeituras no que diz respeito à colaboração política destas em relação às candidaturas para os cargos de Presidente, Governador e para o Congresso Nacional (2002 e 2006). Para as dummies de partido, não foram encontradas evidências significativas que indicassem alguma distinção no comportamento ideológico-partidário em relação ao PMDB. Cabe ressaltar o que ocorreu com a coincidência partidária entre o prefeito e o presidente, pois foi possível constatar uma relação direta entre elas. Cossio (2001) denomina esta situação como "solidariedade ideológica", ou seja, pertencer ao mesmo partido do presidente significa aumento deste tipo de gasto.

Finalmente, nos gastos da função legislativa (tabela 4) existem indícios de manipulações políticas de caráter eleitoral. Para o ano de 2000 os gastos nesta rubrica foram R\$12,08 maiores do que em 1998. Entretanto ocorreu uma redução significativa nos anos de 2002 e 2004 em relação aos anos imediatamente anteriores e posteriores, indicando ser este um item da despesa que também sofreu com o corte nos gastos em detrimento de outros de maior visibilidade eleitoral. Para a postura política, não foram encontradas evidências significativas que indicassem alguma distinção no comportamento ideológico-partidário em relação ao PMDB, à exceção do PP cujos gastos foram, em média, menores que o do PMDB nesta rubrica. Em relação aos gastos com saúde e saneamento (ver tabela 3.9), foram obtidas evidências estatisticamente significativas e com sinal negativo para o ano de 2001. A redução neste item da despesa pode estar relacionada com o superávit financeiro encontrado neste ano, sugerindo que os prefeitos, para conseguir aumentar o saldo em caixa para abertura de créditos adicionais no ano de 2002, cortaram os gastos neste item da despesa. Como este item engloba duas rubricas da despesa e os gastos em saúde são regulamentados pela Constituição, pode-se argumentar que a rubrica "saneamento" é a que mais deve ter sofrido com o corte de gastos neste ano. Não foram encontradas evidências significativas que indicassem alguma distinção no comportamento ideológico-partidário em relação ao PMDB neste item da despesa.

\subsection{RESTOS A PAGAR PROCESSADOS}

Neste item (ver tabela 2), pode-se observar certa preocupação dos policymakers em relação à probabilidade de reeleição, visto que o ano de 2004 é o ano de menor inscrição em restos a pagar. Portanto, preocupados com o ônus das dívidas contraídas (ou mesmo com as exigências da LRF) neste ano, os governantes mostraram-se mais conservadores neste item. 0 superávit financeiro apresenta uma relação inversa (como era esperado), ou seja, para cada $\mathrm{R} \$ 1,00$ de caixa economizado $\mathrm{R} \$$ 0,11 estão relacionados com inscrição em restos a pagar. Os partidos PSDB e PP inscrevem menos em restos a pagar (R\$ 73,00 e R\$ 46,54 per capita respectivamente) que o PMDB. Em relação à postura ideológicopartidária, não foram encontradas evidências significativas que indicassem alguma distinção no comportamento desta variável (partidos de direita e de esquerda).

\subsection{DÍVIDA ATIVA}

Os resultados (ver tabela 2) sugerem certa manipulação eleitoreira nesta variável visto que o ano de 2004 é o ano de menor elevação $(5,21 \%)$ deste item do balanço patrimonial, ou seja, 2004 foi o ano de menor inscrição (ou redução por baixa, prescrição etc) de devedores na dívida ativa municipal. 0 superávit financeiro apresenta uma relação inversa (de acordo com o esperado), ou seja, para cada R\$1,00 de caixa economizado, a dívida ativa diminui $\mathrm{R} \$ 0,22$. Os partidos de esquerda inscrevem, na dívida ativa, menos 
que os de direita. Entretanto a variável dummy para o partido PSB aparece com sinal positivo e estatisticamente significativa, sugerindo que este partido inscreve, na média, mais que o PMDB. Para os demais partidos, não foram encontradas evidências significativas que indicassem alguma distinção no comportamento ideológico-partidário, nesta variável, em relação ao PMDB.

As variáveis “Outras Transferências da União" e "Outras Transferências dos Estados" apresentaram $R^{2}$ muito baixos (variando em torno de $17 \%$ ) e teste $F$ sem significância estatística nas duas metodologias propostas, não sendo consideradas para esta análise.

\section{CONSIDERAÇÕES FINAIS}

Tradicionalmente, os estudos sobre os chamados Ciclos Políticos - ou seja, sobre a existência de relação cíclica entre eleições e variáveis socioeconômicas - adotam abordagem macroeconômica. Outra abordagem do estudo dos ciclos políticos está relacionada com a análise do comportamento dos gastos públicos (à la Rogoff), porém com preocupação basicamente na análise fiscal. Em seu ilustrativo estudo, Preussler e Portugal (2003) vão além destas abordagens e analisam também o comportamento da variável déficit fiscal e sua relação com a ocorrência de eleições. Bittencourt (2002) também utilizou esta abordagem e, além disso, analisou as despesas por função para os estados brasileiros. Meneguin e Bugarin (2001) introduziram a variável dívida consolidada líquida, deixando aberta a via para estudos que tratem mais diretamente de variáveis relacionadas à Contabilidade Pública.

0 presente trabalho se filia aos estudos que buscam uma abordagem quantitativa da Contabilidade Governamental, adotando uma linha de análise sobre informações quantitativas e qualitativas relativas ao eventual comportamento político "oportunista" (ou "cíclico") por parte dos governantes ou dos partidos. A principal inspiração teórica desses estudos se encontra na chamada Teoria dos Ciclos Políticos, desenvolvida e testada em diversos trabalhos acadêmicos. Segundo a teoria, é esperado que haja repetição periódica, ou "eleitoralmente cíclica", de ações visando beneficiar o(s) ator(es) político(s) envolvido(s).

O objetivo do trabalho foi alcançado, uma vez que foi verificado empiricamente o fato de que, no período estudado, o "ano eleitoral" exerceu influência sobre o comportamento da gestão pública nos municípios selecionados. Os resultados sugerem que, para os municípios fluminenses, o calendário eleitoral exerce influência (estatisticamente) significativa sobre determinadas variáveis relativas ao orçamento público, mesmo descontando o efeito específico do que ocorreu em cada município (a população, por exemplo).

Estas manipulações cíclicas também aconteceram em alguns itens da despesa exatamente nos anos de 2002 e 2006, indicando uma movimentação política das prefeituras em períodos pré-eleitorais ou simultâneos a eleições para Governador, Presidente e Congresso Nacional. Os partidos de esquerda gastam mais em agricultura, habitação e urbanismo que os partidos de direita. Nas despesas com transporte observa-se uma redução significativa nos anos de 2002, 2004 e 2006, indicando ser este, um item da despesa que mais sofre com o corte nos gastos em detrimento de outros de maior visibilidade eleitoral. Em relação aos gastos com saúde e saneamento, não foram encontradas evidências estatisticamente significativas para esta variável. Foram encontradas evidências significativas de impulsos positivos na despesa de pessoal e encargos para os anos de 2004 e 2006. A coincidência partidária entre o prefeito e o 
presidente apresenta uma relação inversa, ou seja, pertencer ao mesmo partido do presidente significa uma redução dos gastos municipais, indicando uma espécie de "pacto de ajuste fiscal" entre os níveis de governo. No que tange aos Restos a Pagar Processados, pode-se concluir que existe preocupação dos policymakers em relação à probabilidade de reeleição, visto que o ano de 2004 é o ano de menor inscrição em restos a pagar. Portanto, preocupados com o ônus das dívidas contraídas (ou mesmo com as exigências da LRF) neste ano, os governantes mostraram-se mais conservadores.

Bittencourt (2002, p. 37) afirmou que a habilidade dos eleitores para avaliar as escolhas políticas dos mandatários é diferente entre diferentes cidadãos. Uma parcela do eleitorado está, pode-se dizer, "informada", enquanto que a outra parcela certamente é (mais) "desinformada" e somente é capaz de observar os instrumentos de política pública que diretamente afetam sua utilidade. Assim, por meio de técnicas engenhosas de contabilidade, o governo poderia obstruir a habilidade do eleitor de avaliar a necessidade do endividamento municipal. Para o autor, o acesso livre à mídia pode ajudar os eleitores a superar este problema, mas tais informações requerem não somente recursos (por exemplo, para acesso a rádio, televisão, jornais), mas também destreza e tempo para processá-las, e nenhum destes aspectos é uniformemente distribuído entre os votantes.

Entretanto, em sintonia com as demandas sociais pela maior transparência, a Contabilidade, como ciência e como prática profissional, é que deve assumir seu papel de intermediador da comunicação entre o governo e os interessados nas informações relevantes. A divulgação de informações mais claras, mais confiáveis e mais transparentes caracteriza uma legítima preocupação dos tomadores de decisão, pois os diversos agentes que interagem com o Governo estão cada vez mais interessados na correta aplicação dos tributos que pagam. Portanto, a Contabilidade não pode e nem deve sofrer influências decorrentes de mudanças de governo, mantendo-se fiel às suas premissas básicas como ciência de informação.

A transparência das ações governamentais não limita a busca da accountability apenas à vigência de um dado mandato. No entanto, se não se cumprir aquele requisito, a efetivação de instrumentos institucionais de suporte à accountability pode ficar deveras comprometida, tanto mais porque sem informações confiáveis, relevantes e oportunas, não há possibilidade de os atores sociais ativarem os mecanismos de responsabilização do gestor público.

\section{REFERÊNCIAS}

ALESINA, A. Macroeconomic policy in a two-party system as a repeated game. Quarterly Journal of Economics, v. 102, n. 3, p. 651-678, 1987.

AVELLANEDA, C. N. Municipal performance: does mayoral quality matter? Journal of Public Administration Research and Theory. Disponível em <<doi:10.1093/jopart/mun001>>. Acesso em 20 mar. 2008.

BALEEIRO, A. Uma Introdução à Ciência das Finanças. Rio de Janeiro: Forense, 1998.

BITTENCOURT, J. L. Evidências de ciclos políticos na economia brasileira: um teste para a execução orçamentária dos governos estaduais - 1983/2000. 2002. 142f. Dissertação (Mestrado em Economia) - Programa de Pós-graduação em Economia - UFRS. Porto Alegre. 2002. 
CANÇADO P. L.; ARAUJO Jr., A. F. Economics and Politics: o que determina as chances de reeleição em municípios? O caso das eleições municipais de Minas Gerais - 2000. Ibmec MG. Working Paper 26. Belo Horizonte: Ibmec-MG, 2004.

CARREIRÃO, Y. S. Ideologia e partidos políticos: um estudo sobre coligações em Santa Catarina. Opinião Pública, Campinas, v. 12, n. 1, p. 136-163, 2006.

COLLIS, J.; HUSSEY, R. Pesquisa em administração: um guia prático para alunos de graduação e pós-graduação. 2. ed. Porto Alegre: Bookman, 2005.

COSSIO, F. A. B. O comportamento fiscal dos estados brasileiros e seus determinantes políticos. Economia, v. 2, n.1, p. 207-258, 2001.

DOWNS, A. Economic Theory of Political Action in a Democracy. Journal of Political Economy, v. 65, n. 2, p. 135-150, 1957.

DRAZEN, A. The political business cycles after 25 years. In: BERNANKE, B.; ROGOFF, K. (Eds.). NBER Macroeconomics Annual, Cambridge, Mass.: The MIT Press, p. 75-117, 2001.

FERREIRA, I. F. S.; BUGARIN, M. S. Transferências Voluntárias e Ciclo Político-Orçamentário no Federalismo Fiscal Brasileiro. Ibmec SP. Working Paper 16, 2006.

FREY, B. S.; SCHNEIDER, F. On the modelling of politico-economic interdependence. European Journal of Political Research. v. 3, n. 4, p. 339-360, 1975.

An Empirical Study of Politico-Economic Interaction in the United States. The Review of Economics and Statistics. v. 60, n. 2, p. 174-183, 1978.

Recent Research on Empirical Politico-Economic Models. In D.A. HIBBS, H. FASSBENDER (Eds.), Contemporary Political Economy. Amsterdam: North-Holland Publ. Co., 1981.

GUJARATI, D. Basic Econometrics. 2. ed. New York: McGraw Hill Book Co., 1988.

HIBBS, D. A. Jr. Political parties and macroeconomic policy. American Political Science Review, v. 71, n. 4, p. 1467-1487, 1977.

JUDGE, G. G.; GRIFFITHS, W. E.; et. al. The Theory and Practice of Econometrics. 2. ed. New York: Wiley, 1985.

KALCHHEIM, C.; ROZEVITCH, S. Deficits in local government budgets in Israel: a reflection of political cycles and an expression of local autonomy. Public Budgeting and Finance, v. 10, n. 1, p. 67-77, 1990.

KALECKI, M. Political Aspects of Full Employment (1943), In B. S. FREY (ed.), Political Business Cycles. Cheltenham: Edward Elgar Publ., 1997.

LINDBECK, A. Stabilization Policies in Open Economies with Endogenous Politicians. American Economic Review, v. 66, n. 2, p. 1-19, 1976.

MARTINS, R. C. As Teorias de Ciclos Políticos e o Caso Português. Grupo de Estudos Monetários e Financeiros (GEMF). Universidade de Coimbra. Disponível em: «http://www4.fe.uc.pt/gemf/estudos/pdf/2002/gemf02_05.pdf». Acesso em 25 set. 2007. 
MENEGUIN, F. B; BUGARIN, M. S. Reeleição e política fiscal: um estudo dos efeitos da reeleição nos gastos públicos. Economia Aplicada, v. 5, n. 3, p. 601-622, 2001.

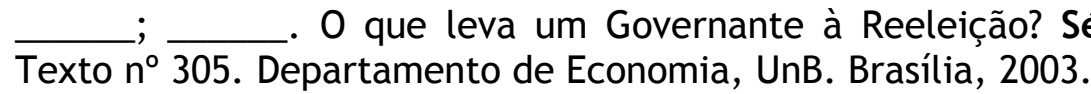

MILESI-FERRETTI, G.-M.; PEROTTI; R.; ROSTAGNO, M. Electoral systems and the composition of public spending. Quarterly Journal of Economics, v. 117, n. 2, p. 609-657, 2002.

NAKAGUMA, M. Y. Ciclos Políticos e Resultados Eleitorais: um estudo sobre o comportamento do eleitor brasileiro. 2006, 78f. Dissertação (Mestrado em Economia) Faculdade de Economia e Administração - Universidade de São Paulo. São Paulo. 2006.

NORDHAUS, W. The political business cycle. Review of Economic Studies, v. 42, n. 2, p. 169-190, 1975.

PETTERSON-LIDBOM, P. (2001) A test of the rational electoral-cycle hypothesis. Disponivel em <www.courses.fas.harvard.edu/ gov3007/Electoralcycle.doc>. Acesso em 25 set. 2007.

PREUSSLER, A. P. S.; PORTUGAL, M. S. Um estudo empírico dos ciclos político-econômicos no Brasil. Análise Econômica, v. 21, n. 40, p. 179-205, 2003.

ROGOFF, K. Equilibrium political budget cycles. American Economic Review, v. 80, n. 1, p. 21-36, 1990.

; SIBERT, A. Elections and macroeconomic policy cycles. Review of Economic Studies, v. 55, n. 1, p. 1-16, 1988.

SAKURAI, S. N. Political business cycles: procurando evidências empíricas para os municípios paulistas (1989 - 2001). 2004. 79 f. Dissertação (Mestrado em Economia) Faculdade de Economia e Administração - Universidade de São Paulo. São Paulo. 2004.

; GREMAUD, A. P. Political business cycles: evidências empíricas para os municípios paulistas (1989 - 2001). Economia Aplicada, v. 11, n. 1, p. 27-54, 2007.

SALVATO, M. A.; ANTUNES, P. C.; ARAUJO Jr, A. F.; SHIKIDA, C. D. Ciclos Políticos: um estudo sobre a relação entre flutuações econômicas e calendário eleitoral no Brasil 19852006. Instituto de Desenvolvimento Humano Sustentável - IDHS - PUC-MG. Working Paper 01-2007. Belo Horizonte. 2007.

SCHUKNECHT, L. Fiscal policy cycles and public expenditure in developing countries. Public Choice, v. 102, n. 1-2, p. 115-130, 2000.

SHI, M.; SVENSSON, J. Political budget cycles: a review of recent developments. Nordic Journal of Political Economy, v. 29, p. 67-76, 2003.

Political budget cycles: do they differ across countries and why? Journal of Public Economics, v. 90, n. 8-9, p. 1367-1389, 2006.

SILVA, L. M. Contabilidade Governamental. São Paulo: Atlas, 2003. 
VEIGA, L. G.; VEIGA, F. J. Ciclos Político-Económicos nos Municípios Portugueses. II Conferência do Banco de Portugal - "Desenvolvimento Económico Português no Espaço Europeu”. Anais da II Conferência do Banco de Portugal. Lisboa. 2004.

VERGNE, C. Democracy, elections and allocation of public expenditures in developing economies. European Journal of Political Economy, v. 25, n. 1, p. 63-77, 2009.

\section{ENDEREÇO DOS AUTORES}

Universidade do Estado do Rio de Janeiro Mestrado em Ciências Contábeis

Rua São Francisco Xavier, 524, $9^{\circ}$ andar - Bloco E - Maracanã

Rio de Janeiro, RJ - Brasil

20550-013 - Caixa-Postal: 68514 